\title{
PENINGKATAN KEAKTIFAN SISWA DAN PRESTASI BELAJAR MATEMATIKA DENGAN MODEL PEMBELAJARAN TIPE TAI (TEAM ASSISTED INDIVIDUALIZATION) PADA KELAS IX-A SEMESTER GANJIL SMP NEGERI 4 MADIUN TAHUN PELAJARAN 2015/2016
}

\author{
Dewi Agust Setyawati \\ SMP Negeri 4 Kota Madiun \\ dewiagustsetyawati@gmail.com
}

\begin{abstract}
Abstrak
Penelitian ini bertujuan untuk mengetahui apakah penerapan metode TAI (Team Assisted Individualization) dapat meningkatkan keaktifan siswa dan prestasi belajar matematika dalam kegitan pembelajaran. Hasil penelitian menunjukkan bahwa pada pembelajaran siklus I siswa aktif dalam kelompok 10 siswa dengan prosentase 33,33\%, siswa yang cukup aktif 6 siswa dengan prosentase $20 \%$, siswa yang kurang aktif 6 siswa dengan prosentase 20\%, siswa yang tidak aktif 8 siswa dengan prosentase 26,67\%. Siswa yang aktif dalam individu 12 siswa dengan prosentase 40\%, siswa yang cukup aktif 5 siswa dengan prosentase 16,67\%, siswa yang kurang aktif 9 siswa dengan prosentase 30\%, siswa yang tidak aktif 4 siswa dengan prosentase 13,33\%. Pada siklus II siswa aktif dalam kelompok 12 siswa dengan prosentase 40\%, siswa yang cukup aktif 7 siswa dengan prosentase $23,33 \%$, siswa yang kurang aktif 6 siswa dengan prosentase 20\%, siswa yang tidak aktif 5 siswa dengan prosentase 16,67\%. Siswa yang aktif dalam individu 14 siswa dengan prosentase 46,67\%, siswa yang cukup aktif 7 siswa dengan prosentase 23,33\%, siswa yang kurang aktif 5 siswa dengan prosentase 16,67\%, siswa yang tidak aktif 4 siswa dengan prosentase 13,33\%. Siklus III siswa aktif dalam kelompok 19 siswa dengan prosentase 63,33\%, siswa yang cukup aktif 8 siswa dengan prosentase 26,67\%, siswa yang kurang aktif 2 siswa dengan prosentase 6,67\%, siswa yang tidak aktif 1 siswa dengan prosentase 3,33\%. Siswa yang aktif dalam individu 18 siswa dengan prosentase 60\%, siswa yang cukup aktif 9 siswa dengan prosentase 30\%, siswa yang kurang aktif 3 siswa dengan prosentase 10\%, siswa yang tidak aktif tidak ada. Hasil lain dari penelitian menunjukkan bahwa pada siklus I siswa yang tuntas belajar hanya 102 siswa dengan prosentase 33,33\%, pada siklus II siswa yang tuntas 17 siswa dengan prosentase 56,67\%, dan pada siklus III mengalami peningkatan yang signifikan siswa yang tuntas menjadi 27 siswa dengan prosentase $90 \%$.
\end{abstract}

Kata Kunci : Team Assisted Individualization; keaktifan; prestasi belajar

\section{PENDAHULUAN}

Pendidikan merupakan suatu sistem yang memiliki kegiatan cukup kompleks, meliputi berbagai komponen yang berkaitan satu sama lain. Jika menginginkan pendidikan terlaksana secara teratur, berbagai elemen (komponen) yang terlibat dalam kegiatan pendidikan perlu dikenali. Pendidikan dapat dilihat dari hubungan elemen peserta didik (siswa), pendidik (guru), dan interaksi keduanya dalam usaha pendidikan. Hubungan antara elemen peserta didik (siswa) dengan pendidik (guru) seharusnya tidak hanya bersifat satu arah saja berupa penyampaian informasi dari guru kepada peserta didik. Proses belajar mengajar justru lebih baik jika dilakukan secara aktif oleh kedua belah pihak yaitu guru dan peserta didik agar terjadi interaksi yang seimbang antara keduanya.

Metematika adalah pelajaran yang paling sulit, membosankan dan membuat 


\author{
JEMS (Jurnal Edukasi Matematika dan Sains) \\ Tersedia online di: http://e-journal.ikippgrimadiun.ac.id/index.php/JEMS \\ Volume 4, Nomor 2, September 2016, hal 115-120
}

kepala menjadi pusing bagi sebagian besar siswa karena mereka akan selalu bertemu dengan angka-angka dan rumus-rumus tanpa adanya permainan dan humor. Apalagi guru yang mengajar matematika ketat dan disiplin atau biasa disebut "killer" akan menambah ketegangan dan ketidakberdayaan siswa terhadap matematika, namun sebenarnya matematika mempunyai peranan dalam perkembangan ilmu pengetahuan dan teknologi. Tetapi karena anggapan sebagian siswa yang demikian menjadikan matematika sebagai hambatan untuk berprestasi.

Mengingat peran matematika yang sangat penting, maka guru dan siswa dituntut untuk menguasai materi matematika dengan baik. Akan tetapi, dikalangan siswa telah berkembang asumsi bahwa pelajaran matematika adalah pelajaran yang sangat sulit. Untuk dipahami bahkan terkesan menakutkan. Munculnya kesulitan pada siswa dalam memahami pelajaran matematika tersebut, tidak lepas dari peranan guru yang dirasa kurang dalam melaksanakan proses pembelajaran.

Model pembelajaran yang sampai saat ini masih sering ditemui adalah model pembelajaran yang bersifat pasif. Dalam hal ini siswa bersikap pasif, karena pembelajaran di dalam kelas masih banyak didominasi oleh guru. Guru lebih banyak menjadikan siswa obyek dari pada subyek. Dalam hal ini pembelajaran akan berkesan sekedar pemindahan pengetahuan dan penyerapan pengetahuan. Pembelajaran seperti itu akan mengakibatkan kurangnya keaktifan siswa dalam pembelajaran, karena siswa hanya melihat, mendengar, dan mencatat materi yang disampaikan oleh guru. Siswa juga akan bersifat individualis, karena kurang dilatih dan diajarkan ketrampilan-ketrampilan sosial yang bermanfaat untuk menjalin hubungan interpersonal antar sesama teman, yang akan mengakibatkan siswa yang pandai menjadi pandai dan siswa yang kurang pandai akan semakin bodoh.

Guru berperan penting untuk meningkatkan motivasi belajar siswa dan menciptakan situasi belajar yang menyenangkan. Mengajarkan matematika pada siswa tidaklah mudah, guru harus membuat siswa menguasai dan memahami konsep matematika.

Proses penguasaan matematika berawal dari suatu pengalaman-pengalaman belajar baik pengalaman umum maupun pengalaman khusus. (Oemar Hamalik, 2004:19) menyebutkan bahwa "Pengalaman adalah sebagai sumber pengetahuan dan ketrampilan bersifat pendidikan yang merupakan suatu kesatuan disekitar tujuan murid, pengalaman pendidikan bersifat kontinu dan interaktif, membantu integrasi pribadi murid-murid. Pada garis besarnya pengalaman itu terbagi menjadi dua yaitu, pengalaman langsung partisipasi sesungguhnya, berbuat dan sebagainya serta pengalaman pengganti seperti penggunaan media.

Didalam proses belajar mengajar, guru harus memiliki strategi belajar agar siswa dapat belajar efektif, efisien dan mengena pada tujuan yang diharapkan. Namun kenyataan di lapangan banyak guru yang tidak menggunakan model-model pembelajaran, mereka kebanyakan menggunakan metode ceramah dalam kegiatan pembelajaran sehingga mengakibatkan kurangnya keaktifan siswa. Salah satu langkah untuk memiliki strategi itu ialah harus menguasai teknik-teknik penyajian atau metode pembelajaran. Metode pembelajaran merupakan suatu bentuk pendekatan pembelajaran yang diarahkan atau diorientasikan pada strategi guru pada proses belajar mengajar.

Tujuan penelitian ini adalah untuk mengetahui peningkatan keaktifan siswa dan prestasi belajar siswa dalam pembelajaran Matematika dengan model pembelajaran tipe TAI (Team Assisted Individualization) pada kelas IX-A semester ganjil SMP Negeri 4 Madiun Tahun Pelajaran 2015/2016

\section{METODE}

Penelitian ini dilaksanakan dengan pendekatan Penelitian Tindakan Kelas (PTK). Dalam melaksanakan penelitian ini, peneliti mengambil lokasi penelitian di SMP Negeri 4 Kota Madiun, yang beralamat di Jl. Abdul Rakhman Saleh no. 3 Kota Madiun. Penelitian tindakan kelas ini akan dilakukan pada bulan 
September sampai dengan bulan Nopember 2015.

Dalam penelitian ini, subyek yang digunakan adalah siswa kelas IX-A SMP Negeri 4 Madiun Tahun Pelajaran 2015/2016 berjumlah 30 siswa terdiri dari 14 siswa lakilaki dan 16 siswa perempuan.

Teknik pengumpulan data yang digunakan adalah dengan metode tes dan observasi. Rencana pelaksanaan penelitian dilakukan dalam 3 siklus. Setiap siklus terdiri dari 4 tahap yaitu perencanaan, tindakan, pelaksanaan tindakan, observasi dan refleksi. Prosedur penelitian tindakan kelas yang akan

Tabel 1. Prosentase Keaktifan Siswa dalam Kelompok dan dalam Individu pada Siklus I Kriteria Keaktifan

\begin{tabular}{lccccccccc}
\multirow{2}{*}{ Siswa Aktif } & \multicolumn{3}{c}{ TA } & \multicolumn{2}{c}{ KA } & \multicolumn{2}{c}{ CA } & \multicolumn{2}{c}{ A } \\
\cline { 2 - 29 } & JS & $\%$ & JS & $\%$ & JS & $\%$ & $\%$ \\
\hline Dalam Kelompok & 8 & 26,67 & 6 & 20 & 6 & 20 & 10 & 33,33 \\
\hline Dalam Individu & 4 & 13,33 & 9 & 30 & 5 & 16,67 & 12 & 40
\end{tabular}

Keterangan:

$\mathrm{TA}=$ Tidak Aktif

$\mathrm{KA}=$ Kurang Aktif

$\mathrm{CA}=$ Cukup Aktif

$\mathrm{A}=$ Aktif

$\mathrm{JS}=$ Jumlah Siswa

Tabel 2. Hasil Ketuntasan Siswa pada Siklus I

\begin{tabular}{ccccc}
\hline \multirow{2}{*}{ Siklus } & \multicolumn{2}{c}{ Tuntas } & \multicolumn{3}{c}{ Tidak Tuntas } \\
\cline { 2 - 5 } & Jumlah Siswa & $\%$ & Jumlah Siswa & $\%$ \\
\hline I & 10 & 33,33 & 20 & 66,67 \\
\hline
\end{tabular}

\section{Siklus II}

Hasil pengamatan pada siklus II berupa lembar observasi keaktifan siswa baik secara individu maupun secara kelompok.

Tabel 3.Prosentase Keaktifan Siswa dalam Kelompok dan dalam Individu pada Siklus II

\begin{tabular}{lccccccccc}
\hline \multirow{2}{*}{ Siswa Aktif } & \multicolumn{9}{c}{ Kriteria Keaktifan } \\
\cline { 2 - 11 } & \multicolumn{3}{c}{ TA } & \multicolumn{1}{c}{ KA } & \multicolumn{1}{c}{ CA } & \multicolumn{2}{c}{ A } \\
\cline { 2 - 10 } & JS & $\%$ & JS & $\%$ & JS & $\%$ & JS & $\%$ \\
\hline Dalam Kelompok & 5 & 16,67 & 6 & 20 & 7 & 23,33 & 12 & 40 \\
\hline Dalam Individu & 4 & 13,33 & 5 & 16,67 & 7 & 23,33 & 14 & 46,67 \\
\hline
\end{tabular}

Keterangan:

$\mathrm{TA}=$ Tidak Aktif

$\mathrm{KA}=$ Kurang Aktif

$\mathrm{CA}=$ Cukup Aktif

$\mathrm{A}=$ Aktif

$\mathrm{JS}=$ Jumlah Siswa 
Tersedia online di: http://e-journal.ikippgrimadiun.ac.id/index.php/JEMS

Volume 4, Nomor 2, September 2016, hal 115-120

1) Prestasi Belajar Siswa

Hasil post tes pada siklus II mengalami peningkatan dari pada siklus I yang mengakibatkan

Tabel 4. Hasil Ketuntasan Siswa pada Siklus II

\begin{tabular}{ccccc}
\hline \multirow{2}{*}{ Siklus } & \multicolumn{2}{c}{ Tuntas } & \multicolumn{3}{c}{ Tidak Tuntas } \\
\cline { 2 - 5 } & Jumlah Siswa & $\%$ & Jumlah Siswa & $\%$ \\
\hline II & 17 & 56,67 & 13 & 43,33 \\
\hline
\end{tabular}

Siklus III

1) Keaktifan Siswa

Hasil pengamatan pada siklus III tentang keaktifan siswa secara individu siklus II. ketuntasan siswa juga mengalami perubahan dibandingkan dengan siklus I.

Tabel 5. Prosentase Keaktifan Siswa dalam Kelompok dan dalam Individu pada Siklus III

\begin{tabular}{lccccccccc}
\hline \multirow{2}{*}{ Siswa Aktif } & \multicolumn{9}{c}{ Kriteria Keaktifan } \\
\cline { 2 - 11 } & \multicolumn{2}{c}{ TA } & \multicolumn{2}{c}{ KA } & \multicolumn{1}{c}{ CA } & \multicolumn{2}{c}{ A } \\
\cline { 2 - 11 } & JS & $\%$ & JS & $\%$ & JS & $\%$ & JS & $\%$ \\
\hline Dalam Kelompok & 1 & 33,3 & 2 & 6,67 & 8 & 26,67 & 19 & 63,33 \\
\hline Dalam Individu & - & - & 3 & 10 & 9 & 30 & 18 & 60 \\
\hline
\end{tabular}

Keterangan:

$\mathrm{TA}=$ Tidak Aktif

$\mathrm{KA}=$ Kurang Aktif

$\mathrm{CA}=$ Cukup Aktif

$\mathrm{A}=$ Aktif

JS = Jumlah Siswa

2) Prestasi Belajar Siswa

Hasil post tes pada sikus III mengalami peningkatan dari pada siklus I dan II yang mengakibatkan

dan kelompok mengalami peningkatan jika dibandingkan dengan siklus I dan

Tabel 6. Hasil Ketuntasan Belajar Siswa pada Siklus III

\begin{tabular}{ccccc}
\hline \multirow{2}{*}{$\begin{array}{c}\text { Siklu } \\
\text { S }\end{array}$} & \multicolumn{2}{c}{ Tuntas } & \multicolumn{3}{c}{ Tidak Tuntas } \\
\cline { 2 - 5 } & $\begin{array}{c}\text { Jumlah } \\
\text { Siswa }\end{array}$ & $\%$ & Jumlah Siswa & $\%$ \\
\hline III & 27 & 90 & 3 & 10
\end{tabular}

\section{PEMBAHASAN}

Melalui hasil penelitian pada siklus I, II, dan III menunjukkan adanya peningkatan prestasi belajar matematika dengan menerapkan metode pembelajaran tipe TAI (Team Assisted Individualization). Hal ini disebabkan penerapan metode TAI (Team Assisted ketuntasan siswa pada siklus III mengalami perubahan dibandingkan dengan siklus I dan II.

Individualization) dapat mempermudah siswa dalam memahami materi dan tidak membuat siswa menjadi bosan dalam mengikuti npelajaran matematika.

1) Keaktifan Siswa dalam Kelompok dan Individu 
JEMS (Jurnal Edukasi Matematika dan Sains)

Tersedia online di: http://e-journal.ikippgrimadiun.ac.id/index.php/JEMS

Volume 4, Nomor 2, September 2016, hal 115-120

Tabel 7. Prosentase Keaktifan Siswa dalam Kelompok

\begin{tabular}{|c|c|c|c|c|c|c|c|c|}
\hline \multirow{3}{*}{ Siklus } & \multicolumn{8}{|c|}{ Kriteria Keaktifan } \\
\hline & \multicolumn{8}{|c|}{ Dalam Kelompok } \\
\hline & TA & $\%$ & KA & $\%$ & $\mathrm{CA}$ & $\%$ & A & $\%$ \\
\hline I & 8 & 26,67 & 6 & 20 & 6 & 20 & 10 & 33,33 \\
\hline II & 5 & 16,67 & 6 & 20 & 7 & 23,33 & 12 & 40 \\
\hline III & 1 & 33,3 & 2 & 6,67 & 8 & 26,67 & & 63,33 \\
\hline \multicolumn{9}{|c|}{ Tabel 8.Prosentase Keaktifan Siswa dalam Individu } \\
\hline \multirow{3}{*}{ Siklus } & \multicolumn{8}{|c|}{ Kriteria Keaktifan } \\
\hline & & & & alam I & ndivi & & & \\
\hline & TA & $\%$ & KA & $\%$ & CA & $\%$ & A & $\%$ \\
\hline I & 4 & 13,33 & 9 & 30 & 5 & 16,67 & 12 & 40 \\
\hline II & 4 & 13,33 & 5 & 16,67 & 7 & 23,33 & 14 & 46,67 \\
\hline III & - & - & 3 & 10 & 9 & 30 & 18 & 60 \\
\hline
\end{tabular}

Keterangan:

$\mathrm{TA}=$ Tidak Aktif

$\mathrm{KA}=$ Kurang Aktif

$\mathrm{CA}=$ Cukup Aktif

$\mathrm{A}=$ Aktif

2) Prestasi Belajar Siswa

Berdasarkan hasil tes pada siklus

I, II, dan III dapat disajikan dalam

bentuk tabel sebagai berikut.

Tabel 9.Ketuntasan Belajar Siswa

\begin{tabular}{ccccc}
\hline \multirow{2}{*}{ Siklus } & \multicolumn{4}{c}{ Ketuntasan Belajar } \\
\cline { 2 - 5 } & Tuntas & $\%$ & Tidak Tuntas & $\%$ \\
\hline I & 10 & 34,28 & 20 & 65,72 \\
\hline II & 17 & 57,5 & 13 & 42,5 \\
\hline III & 27 & 91,4 & 3 & 8,6 \\
\hline
\end{tabular}

Berdasarkan tabel di atas dapat diketahui siswa yang tuntas di kelas IX-A pada siklus I sebanyak 10 siswa dengan prosentase $34,28 \%$, sedangkan siswa yang tidak tuntas 20 siswa dengan prosentase $65,72 \%$. Pada siklus II siswa yang tuntas sebanyak 17 siswa dengan prosentase $57,5 \%$, sedangkan siswa yang tidak tuntas 13 siswa dengan prosentase $42,5 \%$. Pada siklus III siswa yang tuntas sebanyak 27 siswa dengan prosentase $91,4 \%$, sedangkan siswa yang tidak tuntas sebanyak 3 siswa dengan prosentase $8,6 \%$.

Dengan demikian dapat disimpulkan bahwa penerapan model pembelajaran tipe TAI (Team Assisted Individualization) pada pokok bahasan bangun ruang sisi lengkung dapat meningkatkan hasil belajar

matematika kelas IX-A SMP Negeri 4 Madiun.

\section{KESIMPULAN DAN SARAN}

Berdasarkan rumusan masalah dan hasil penelitian dapat disimpulkan bahwa pemmbelajaran dengan menggunakan metode TAI (Team Assisted Individualization) yang diterapkan di kelas IX-A siswa SMP Negeri 4 Madiun pokok bahasan bangun ruang sisi lengkung dapat meningkatkan keaktifan siswa selama pembelajaran.

Penerapan model pembelajaran tipe TAI (Team Assisted Individualization) pada pokok bahasan bangun ruang sisi lengkung dapat meningkatkan prestasi 
belajar siswa kelas IX-A siswa SMP Negeri 4 Madiun.

Pembelajaran dengan menggunakan

metode TAI (Team Assisted Individualization) sangat tepat, karena metode TAI (Team Assisted Individualization) dapat mempermudah siswa dalam menghitung bilangan. Penerapan metode ini juga dapat digunakan sebagai alternatif pengajaran yang cukup baik bagi guru dan metode yang menyenangkan bagi siswa, sehingga dapat meningkatkan keaktifan siswa dan prestasi belajar matematika terutama pada materi bangun ruang sisi lengkung.Dalam upaya meningkatkan prestasi belajar matematika hendaknya sekolah mendukung pelaksanaan pembelajaran dengan metode TAI (Team Assisted Individualization). Peneliti lain yang akan melakukan penelitian sejenis hendaknya mengambil materi yang lain atau materi yang sama dengan populasi yang lebih luas sehingga kesimpulan yang diambil akan lebih akurat.

\section{Daftar Pustaka}

Baharuddin, Esa Nur Wahyuni. (2007). Teori belajar \& Pembelajaran. Yogjakarta: Ar-Ruzz Media

Hamzah B. Uno. (2007). Model Pembelajaran. Jakarta: Bumi Aksara

Hudoyo, Herman. (1990). Strategi Belajar Mengajar. Malang: IKIP Malang

Husaini Usman, Purnomo Setiady Akbar. (2006). Pengantar Statistika. Jakarta: Sinar Grafika

Mulyono Abdurahman. (1999). Kurikulum dan Pembelajaran. Jakarta: Bumi Aksara .(2004). Pendidikan Bagi Anak Berkesulitan Belajar. Jakarta: Rineka Cipta

Nur, Muhammad. (2005). pembelajaran Kooperatif. Surabaya: Pusat sains dan Matematika Sekolah UNESA
Nurhadi. (2004). Kurikulum 2004. Pertanyaan dan Jawaban. Jakarta: PT Gramedia Widiasarana Indonesia

(2004). Pembelajaran Kontekstual (CTL) dan Penerapannya dalam KBK. Malang: Universitas Negeri Malang

Slameto. (2003). Belajar dan Faktor-faktor Yang Mempengaruhinya. Jakarta: PT Rineka Cipta

Suharsimi Arikunto. (2002). Prosedur Penelitian Suatu Pendekatan Praktis. Jakarta: Rineka Cipta . (2006). Penelitian Tindakan Kelas. Jakarta: PT Bumi Aksara 